\title{
Outcome of carotid endarterectomy on the basis of patient sex: Is there a difference?
}

\author{
Nancy L. Harthun, MDa \\ Vasana Cheanvechai, $\mathrm{MD}^{\mathrm{b}}$ \\ Linda M. Graham, MD ${ }^{\mathrm{C}}$ \\ Julie A. Freischlag, $M D^{d}$ \\ Vivian Gahtan, MD
}

See related editorials on pages 314,318 , and 325 .

From the Division of TCV Surgery, ${ }^{a}$ University of Virginia Health System, Charlottesville, Va; the Division of Vascular Surgery, ${ }^{\mathrm{b}}$ University of Maryland, Baltimore, Md; the Department of Vascular Surgery, ${ }^{\mathrm{c}}$ the Cleveland Clinic Foundation, Cleveland, Ohio; the Department of Surgery, ${ }^{\mathrm{d}}$ Johns Hopkins School of Medicine, Baltimore, Md; and the Section of Vascular Surgery, ${ }^{\mathrm{e}}$ Yale University School of Medicine, New Haven, Conn.

This is a project of the Society of Vascular Surgery, Committee on Women's Issues.

Received for publication Sept 29, 2003; accepted for publication Oct 6, 2003.

Address for reprints: Vivian Gahtan, MD, SUNY Upstate Medical University College of Medicine, Department of Surgery, 750 East Adams St, Syracuse, NY 13210 (Email: gahtanv@upstate.edu).

J Thorac Cardiovasc Surg 2004;127:322-4

$0022-5223 / \$ 30.00$

Copyright ( $\odot 2004$ by The American Association for Thoracic Surgery

doi:10.1016/j.jtcvs.2003.10.021

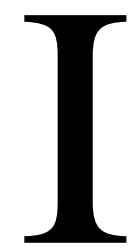

$\mathrm{n}$ the United States 700,000 strokes occur each year, and these are the third leading cause of death. ${ }^{1}$ Of the 167,661 deaths from stroke reported by the American Heart Association in 2000, 102,892 were among women and 64,769 were among men. ${ }^{1}$ Women $(53 \%)$ in the United States are reported to experience strokes more frequently than men but at a more advanced age. ${ }^{1}$ When examining sex differences, the prevalence of stroke must be controlled for age because women have a longer life expectancy, and the occurrence of stroke increases dramatically with increasing age. In the year 2000 the ageadjusted first-event stroke rates (per 100,000) were as follows: 167 for white men, 138 for white women, 323 for African American men, and 260 for African American women. Age-standardized mortalities for ischemic stroke were higher for women age 65 years and older from 1995 through 1998. ${ }^{1}$ Most (61\%) strokes are reported to be caused by atherothrombotic events. ${ }^{1}$ Atherosclerosis and stenosis of the carotid arteries are known clinical entities associated with stroke. The overall prevalence of carotid stenosis in patients who experience ischemic strokes, however, remains unknown.

Most aspects regarding carotid endarterectomy (CEA) for stroke prevention have been examined. Patient eligibility, surgical indications, technical considerations, and detailed outcome expectations have been defined. Unfortunately, most of this scientific effort has assumed that men and women have no significant difference in outcome after CEA or the natural history of carotid stenosis. Challenges to this assumption have been raised. The Asymptomatic Carotid Atherosclerosis Study, ${ }^{2}$ in 1995, sparked a debate that continues. The purpose of the study was to compare medical and surgical treatment of patients with asymptomatic internal carotid artery stenosis greater than or equal to $60 \%$. Subjects were randomly assigned to medical or surgical treatment and separated by the degree of stenosis identified. They were followed for 2.7 years for cerebrovascular events, which included stroke, transient ischemic attack, and death. Approximately one third of the total patients enrolled were women (568/1659); however, conclusions were made that questioned the protection CEA offers asymptomatic women. The 5-year stroke risk-reduction rate was $66 \%$ for men and only $17 \%$ for women. The authors suggested that this muted benefit for women occurred because they had a higher incidence of perioperative events $(3.6 \%)$.

Three years later, post hoc analysis of patients with symptomatic carotid stenosis analyzed in the North American Symptomatic Carotid Endarterectomy Trial also suggested that women experienced less benefit from CEA. ${ }^{3}$ This prospective study demonstrated that women with $50 \%$ to $69 \%$ symptomatic stenosis had a lower stroke risk when managed medically. Interestingly, this study did not demonstrate higher perioperative stroke and death rates in women when compared with men. This study also enrolled relatively few women (63) compared with men (137).

The conclusion that women derive less benefit from CEA is viewed with some skepticism. Despite the excellent design of the North American Symptomatic Carotid Endarterectomy Trial and Asymptomatic Carotid Atherosclerosis Study in 
TABLE 1. Perioperative and late outcomes of carotid endarterectomy comparing men and women

\begin{tabular}{|c|c|c|c|c|}
\hline Reference & Asymptomatic women & Asymptomatic men & Symptomatic women & Symptomatic men \\
\hline \multirow[t]{4}{*}{ Mattos and colleagues ${ }^{4}$} & $\mathrm{n}=154(33 \%)$ & $\mathrm{n}=247(33 \%)$ & $\mathrm{n}=311(67 \%)$ & $\mathrm{n}=492(67 \%)$ \\
\hline & Death $=0(0 \%)$ & Death $=2(0.8 \%)$ & Death $=1(0.3 \%)$ & Death $=4(0.8 \%)$ \\
\hline & $C V A=1(0.6 \%)$ & CVA $=3(1.2 \%)$ & CVA $=9(2.9 \%)$ & CVA $=22(4.5 \%)$ \\
\hline & $\begin{array}{l}5-y \text { death }=9(18 \%) \\
5-y \text { CVA }=(0 \%)\end{array}$ & $\begin{array}{l}5-y \text { death }=38(38 \%) \\
5 \text {-y CVA }=(10 \%)\end{array}$ & $\begin{array}{l}5-y \text { death }=40(28 \%) \\
5-y \text { CVA }=(18 \%)\end{array}$ & $\begin{array}{l}5-y \text { death }=94(38 \%) \\
5-y \text { CVA }=(15 \%)\end{array}$ \\
\hline \multirow[t]{3}{*}{ Sarac and colleagues ${ }^{5}$} & $\mathrm{n}=787(69 \%)$ & $\mathrm{n}=1586(70 \%)$ & $\mathrm{n}=361(31 \%)$ & $\mathrm{n}=688(30 \%)$ \\
\hline & Death $=7(0.9 \%)$ & Death $=12(0.8 \%)$ & Death $=7(1.9 \%)$ & Death $=8(1.2 \%)$ \\
\hline & CVA $=17(2.2 \%)^{*}$ & CVA $=16(1 \%)^{*}$ & $C V A=12(3.3 \%)$ & $C V A=20(2.9 \%)$ \\
\hline \multirow[t]{3}{*}{ Rockman and colleagues 6} & $\mathrm{n}=332(33 \%)$ & $\mathrm{n}=444(30 \%)$ & $\mathrm{n}=659(67 \%)$ & $\mathrm{n}=1041(70 \%)$ \\
\hline & CVA $=4(1.2 \%)$ & $C V A=9(2.0 \%)$ & $C V A=20(3.0 \%)$ & $C V A=25(2.5 \%)$ \\
\hline & Death $=5(0.5 \%) \dagger$ & Death $=16(1.1 \%) \dagger$ & & \\
\hline \multirow[t]{3}{*}{ Akbari and colleagues ${ }^{7}$} & $\mathrm{n}=263(51 \%)$ & $\mathrm{n}=343(44 \%)$ & $\mathrm{n}=257(49 \%)$ & $n=453(56 \%)$ \\
\hline & $C V A=3(0.6 \%)$ & $C V A=3(0.4 \%)$ & CVA $=6(2.3 \%)$ & CVA $=7(1.6 \%)$ \\
\hline & Death $=1(0.2 \%) \dagger$ & Death $=3(0.4 \%) \dagger$ & & \\
\hline \multirow[t]{3}{*}{ Sternbach and Perler ${ }^{8}$} & $\mathrm{n}=66(44 \%)$ & $\mathrm{n}=83(56 \%)$ & NA & NA \\
\hline & Death $=0(0 \%)$ & Death $=0(0 \%)$ & & \\
\hline & $C V A=0(0 \%)$ & CVA $=1(1.3 \%)$ & & \\
\hline \multirow[t]{3}{*}{ James and colleagues $^{9}$} & $\mathrm{n}=64(51 \%)$ & $\mathrm{n}=89(45 \%)$ & $\mathrm{n}=61(49 \%)$ & $\mathrm{n}=110(55 \%)$ \\
\hline & Death $=1(0.8 \%) \dagger$ & Death $=0(0 \%) \dagger$ & & \\
\hline & $C V A=3(2.4 \%) \dagger$ & $C V A=3(1.5 \%) \dagger$ & & \\
\hline \multirow[t]{3}{*}{ Schneider and colleagues ${ }^{1}$} & $\mathrm{n}=46(30 \%)$ & $\mathrm{n}=63(23 \%)$ & $\mathrm{n}=109(70 \%)$ & $n=208(67 \%)$ \\
\hline & Death $=1(0.7 \%) \dagger$ & Death $=0(0 \%) \dagger$ & & \\
\hline & CVA $=5(3.2 \%) \dagger$ & $C V A=4(1.5 \%) \dagger$ & & \\
\hline
\end{tabular}

CVA, Cerebrovascular accident or stroke. Death refers to 30-day mortality. Five-year death refers to death from any cause during long-term follow-up. Five-year CVA refers to ipsilateral stroke during long-term follow-up.

${ }^{*} P<.05$, asymptomatic women compared with asymptomatic men.

tCombined symptomatic and asymptomatic patients.

terms of prospective enrollment and random assignment to treatment groups, these studies were not designed with the purpose of exploring differences in outcome on the basis of sex. This fact is demonstrated in the most glaring flaw of both studies, the relatively low number of women enrolled. Proper examination of the outcomes of CEA would require a large sample size because of the low rate of events.

A number of surgeons published their institution's results regarding women who underwent CEA (Table 1). ${ }^{1,4-9}$ Patients were generally a mixed population, with symptomatic and asymptomatic disease. For example, Mattos and colleagues, ${ }^{4}$ from the Southern Illinois University School of Medicine, examined long-term outcome after CEA. They analyzed data from 454 women and 739 men who underwent CEA for asymptomatic and symptomatic stenoses. Follow-up data were available for $70 \%$ of patients up to 8 years after surgical intervention. No significant differences were reported to have occurred in perioperative stroke and mortality for men and women when divided into symptomatic and asymptomatic groups. The data showed long-term, stroke-free survival was the same for men and women after CEA. Also, long-term survival after CEA was improved for women in both the symptomatic and asymptomatic groups when compared with men. ${ }^{4}$

Sarac and associates ${ }^{5}$ published a series from the Cleveland Clinic Foundation of 3077 patients (1148 women) in
2002. Data were available for the perioperative period only, and therefore no long-term benefit of CEA could be determined; however, women without symptoms before CEA had a significantly higher stroke rate than men. Transient ischemic attack rates and mortalities for the asymptomatic group were not significantly different between women and men. However, they concluded that even with the higher stroke rate in asymptomatic women, CEA should be performed because complication rates were acceptable (2.2\% stroke rate). No difference was reported between symptomatic men and women for perioperative transient ischemic attack rates, stroke rates, and mortalities.

Rockman and coworkers ${ }^{6}$ from New York Medical Center reported their series of CEAs (991 women and 1485 men) for symptomatic and asymptomatic patients. No differences in perioperative stroke rates between men and women were present, even when divided by preoperative symptoms. In fact, the subgroup with the lowest stroke rate was asymptomatic women, although this difference did not reach statistical significance. Only in-hospital data were available, and therefore no determination of long-term benefit of CEA could be made. Akbari and colleagues, ${ }^{7}$ Sternbach and Perler, ${ }^{8}$ James and associates, ${ }^{9}$ and Schneider and coworkers ${ }^{10}$ also published similar reports that demonstrated no statistical difference in perioperative stroke and mortality for women at their institution. 
Differences have been reported between men and women in the rate of early ( $<5$ years) restenosis after CEA. Most of the studies performed on the subject of restenosis examined the type of closure (patch or primary) or patch material used (polytetrafluoroethylene, vein, or Dacron). Most of these reports demonstrated that women had a significantly higher restenosis rate than men. Four studies associated the higher rate of early restenosis in women only with primary closure, ${ }^{11-14}$ and 2 other studies reported this difference for vein $^{15,16}$ and Dacron ${ }^{16}$ patch closures as well. The primary objective of these studies was not to examine differences between men and women, which limits the ability to explain why this difference exists. One report measured the internal carotid artery diameter and reported no significant difference in diameter between men and women undergoing CEA. ${ }^{12}$ In the same study no significant diameter difference was found when comparing arteries in which restenosis developed after CEA and arteries that remained widely patent. It should be noted that this issue remains controversial. Despite the large number of reports that support a sex-based difference in development of early carotid restenosis, several studies did not demonstrate such a difference. ${ }^{17-19}$

As evidenced by this review, it remains unclear whether women derive the same benefit as men from CEA. This issue needs to be resolved for 3 main reasons.

1. It restricts progress toward defining a pathophysiologic basis for any sex-based differences. For example, it has been suggested that women's arteries are smaller, which might predispose women to thrombosis after CEA, ${ }^{2}$ although this has not been a consistent finding. ${ }^{12}$ Additionally, some data suggest that use of hormone replacement therapy might predispose women to perioperative stroke. ${ }^{20}$

2. Further examination of the true benefits of CEA in women needs to be addressed because the debate itself might have an effect on patient selection for this procedure. Consistent with this concern, several reports suggest CEA is not performed for women who would meet the conventional criteria for surgical intervention. ${ }^{21,22}$

3. As new therapies for carotid stenosis are developed, they should be examined properly for men and women. For example, percutaneous stenting of carotid artery stenosis as primary treatment for asymptomatic patients is being evaluated currently in clinical trials.

If sex-based differences for standard carotid therapy were better understood, these clinical trials could potentially be improved to also examine these factors.

\section{References}

1. American Heart Association. Heart disease and stroke statistics-2003 update. Dallas, Tex: American Heart Association; 2002.

2. Executive Committee for the Asymptomatic Carotid Atherosclerosis Study. Endarterectomy for asymptomatic carotid artery stenosis. JAMA. 1995;273:1421-8.

3. Barnett HJM, Taylor DW, Eliasziw M, Fox AJ, Ferguson GG, Haynes $\mathrm{RB}$, et al. Benefit of carotid endarterectomy in patients with symptomatic moderate or severe stenosis. N Engl J Med. 1998;339:1415-25.

4. Mattos MA, Summer DS, Bohannon WT, Parra J, McLafferty RB, Karch LA, et al. Carotid endarterectomy in women: challenging the results from ACAS and NASCET. Ann Surg. 2001;234:438-46.

5. Sarac T, Hertzer NR, Mascha EJ, O'Hara PJ, Krajewski LP, Clair DG, et al. Gender as primary predictor of outcome after carotid endarterectomy. J Vasc Surg. 2002;35:748-53.

6. Rockman CB, Castillo J, Adelman MA, Jacobowitz GR, Gagne PJ, Lamparello PJ, et al. Carotid endarterectomy in female patients: are the concerns of the asymptomatic carotid atherosclerosis study valid? $J$ Vasc Surg. 2001;33:236-41.

7. Akbari CM, Pulling MC, Pomposelli FB, Gibbons GW, Campbell DR, LoGerfo FW. Gender and carotid endarterectomy: does it matter? $J$ Vasc Surg. 2000;31:1103-9.

8. Sternbach Y, Perler BA. The influence of female gender on the outcome of carotid endarterectomy: a challenge to the ACAS findings. Surgery. 2000;127:272-5.

9. James DC, Hughes JD, Mills JL, Westerband A. The influence of gender on complications of carotid endarterectomy. Am J Surg. 2001; 182:654-7.

10. Schneider JR, Droste JS, Golan JF. Carotid endarterectomy in women versus men: patient characteristics and outcomes. J Vasc Surg. 1997; 25:890-8.

11. Mattos MA, van Bemmelen PS, Barkmeier LD, Hodgson KJ, Ramsey DE, Sumner DS. Routine surveillance after carotid endarterectomy: does it affect clinical management? J Vasc Surg. 1993;17:819-31.

12. Anderson A, Padayachee TS, Sandison AJP, Modaresi KB, Taylor PR. The results of routine primary closure in carotid endarterectomy. Cardiovasc Surg. 1999;7:50-5.

13. AbuRahma AF, Robinson PA, Saiedy S, Khan JH, Boland JP. Prospective randomized trial of carotid endarterectomy with primary closure and patch angioplasty with saphenous vein, jugular vein, and polytetrafluoroethylene: long-term follow-up. J Vasc Surg. 1998;27: 222-34.

14. Eikelboom BC, Ackerstaff RGA, Hoeneveld H, Ludwig JW, Teeuwen $\mathrm{C}$, Vermeulen FEE, et al. Benefits of carotid patching: a randomized study. J Vasc Surg. 1988;7:240-7.

15. Archie JP Jr. Reoperations for carotid artery stenosis: role of primary and secondary reconstructions. J Vasc Surg. 2001;33:495-503.

16. Johnson CA, Tollefson DFJ, Olsen SB, Andersen CA, McKee-Johnson J. The natural history of early recurrent carotid artery stenosis. Am J Surg. 1999;177:433-6.

17. Ricotta JJ, O'Brien-Irr MS. Conservative management of residual and recurrent lesions after carotid endarterectomy: Long-term results. $J$ Vasc Surg. 1997;26:963-72.

18. Ladowski JS, Sinabery LM, Peterson D, Peterson AC, Deschner WP. Factors contributing to recurrent carotid disease following carotid endarterectomy. Am J Surg. 1997;174:118-20.

19. Nene S, Moore W. The role of patch angioplasty in prevention of early recurrent carotid stenosis. Ann Vasc Surg. 1999;13:169-73.

20. Lane JS, Shekherdimian S, Moore WS. Does female gender or hormone replacement therapy affect early or late outcome after carotid endarterectomy? J Vasc Surg. 2003;37:568-74.

21. DiBardino D, Vicente DC, Kazmers A. Is there differential access to carotid endarterectomy based on gender? Ann Vasc Surg. 2000;14: 340-2.

22. Kapral MK, Redelmeier DA. Carotid endarterectomy for women and men. J Womens Health Gend Based Med. 2000;9:987-94. 